\title{
COMO "DECÍAMOS DICIENDO": CONVERSACIONES CON JOHN MURRA EN UNA TARDE DE INVIERNO
}

\author{
María N. Marsilli ${ }^{1}$
}

Me siento a trabajar en este texto en una pausa de mis office hours (horario de atención a estudiantes) que me deja mi apretado horario, un hiato escuálido entre una clase y otra. En algunos minutos llegará Kathryn, mi advisee, quien ha pedido verme para hablar sobre quién sabe qué cosa. "Siempre hay algo nuevo con ella", pienso, y me siento frente al computador a hacer memoria.

Hacía frío y llovía en Santiago ese 30 de julio de 1989. Provinciana sin redención, yo había luchado por más de una hora con la locomoción pública de la capital, todavía más caótica e intermintente en día feriado a causa de la votación. Día de plebiscito en Chile y yo me enfurruñaba en mi frustración y angustia durante todo el camino desde La Reina hasta el centro de Santiago. Buses a horarios alocados, trenes de metro imposibles de abordar, empujones varios y, por sobre todo, la certeza de que John Murra estaba ya casi una hora esperándome en la esquina de Miraflores con Alameda. Ya seguramente estaría harto de esperarme, dispuesto a enrostrarme mi impuntualidad apenas me viera, pensaba con horror. "Murra es tremendo con los que llegan tarde", me había dicho uno de sus discípulos. En alguna conferencia, yo lo había visto fulminar con la mirada a algún estudiante que había osado entrar a la sala cuando su charla ya había comenzado. Dentro del vagón del metro asfixiante, la angustia me hacía sentir puntadas en el estómago.

Estación Santa Lucía. “Finalmente!”, pensé mientras trataba de bajarme a empujones. Corrí hacia la esquina, sujetando como podía mochila y paraguas. John Murra estaba allí, con la espalda apoyada en el muro. Apenas me vio, levantó una mano para saludarme. " ¿Te costó encontrar locomoción, Mamay?”, me preguntó con una sonrisa. Yo asentí, tratando de normalizar la respiración. "Me imaginé", me dijo, sin borrar la sonrisa. “¿Tienes hambre?”. Sólo entonces reparé que en día de plebiscito todo estaría cerrado. La angustia dio paso a una sensación de hambre. "Si", le dije, y empezamos a caminar.

Caminamos lentamente por Miraflores, buscando algún restaurante. De repente, John Murra lanza la pregunta que yo había estado esperando. “QQué vas a hacer con tu vida, Mamay?”, me dice y yo, en respuesta, atino sólo a responder, lo único que tenía claro: "Quiero estudiar fuera de Chile", le digo mecánicamente. "En USA", añado para no parecer completamente estúpida. "Ya veo", me dice él, sin comentar la impertinente vaguedad de mis planes. "Por Miraflores no vamos a encontrar nada abierto creo yo", agrega descuidadamente. "No, creo que no", digo yo para aliviar la tensión del momento. "Mamay, por allá queda la calle Victoria Subercaseaux", me indica apuntando hacia el Este. "Sí, lo sé", contesto en un intento de simular familiaridad con el centro de Santiago. Seguimos caminando y tomamos calle Monjitas.

A mitad del trayecto, cerca de calle San Antonio, Murra me fulmina con una pregunta en la cual yo no había pensado: “ ¿Y dónde en USA quieres ir a estudiar? Al ver mi cara perpleja, él añade: "Porque, como sabes, USA es muy grande, las universidades muy diferentes y el sistema educacional cambia mucho de un Estado a otro". No había pensado en eso; sólo después de un par de preguntas y unas pocas cuadras de caminata, los planes para el resto de mi vida tocaban un punto muerto. "Debemos pensar, Mamay, debemos pensar", me dice él con tono paternal. Después de sus preguntas, yo sólo puedo pensar en la inmensidad de mi ignorancia.

Seguimos caminando y atravesamos calle Bandera. Todo está cerrado, no hay ni siquiera un café abierto y ya el hambre me impide concentrarme. "Debemos pensar como agentes de la historia, no como víctimas de ella", dice él con convicción. Mientras tanto, yo sólo quiero hallar un lugar donde esconderme. “¿Dónde puede haber un

$\overline{1}$ John Carroll University, History Department, 20700 North Park Boulevard, University Heights, OH 44118, USA. mmarsilli@jcu.edu 
restaurante abierto?", dice él, simulando no notar mi vergüenza.

De repente, sin preámbulos, me dice: "Debo advertírtelo, Mamay”. “QQué cosa?”, pregunto yo. "Te vas de Chile porque quieres irte, nadie te obliga", acota. "Te volverás ciudadana de ninguna parte", añade enseguida. "Eso involucra dolor, es mejor que lo sepas ya", agrega serio. "Sabe de lo que habla", me digo a mí misma. "No me importa" le respondo con la irresponsabilidad típica de los veinte y algo años. Él se limita a asentir y seguimos caminando.

En calle Monjitas con Bandera, John Murra se detiene. "Ir a estudiar a USA es sólo el inicio de tus planes, Mamay", me dice. Y añade mirando alrededor, orientándose, "después deberás comenzar de veras tu carrera". Se vuelve, con una sonrisa encantadora. "Tú no sólo investigas bien, también enseñas bien, yo te he visto", me dice, tratando de reconfortarme. Murra me había visto presentar en un par de congresos, es verdad. Nunca se me había ocurrido pensar que yo podía enseñar. "Pero lo que yo quiero es investigar", pienso sin decirle nada. "Enseñanza e investigación van de la mano", me dice él como si hubiera leído mi mente. "Una cosa alimenta a la otra". No era la primera ni la última vez que semejante cosa ocurría. John Murra a menudo asustaba a la gente con su capacidad de leer los pensamientos ajenos como un libro abierto. "Quien enseña bien tiene la mitad de la pelea ganada; nunca se te olvide, Mamay", me dice. "¿Sabes que la calle Victoria Subercaseaux queda por allá, verdad?, me dice apuntando nuevamente hacia el este. "Sí, ya me lo dijo, profesor", le respondo confundida. “¿Por qué me vuelve a preguntar lo mismo?", pienso, y siento un vago temor de que lea mi pensamiento otra vez.

"En USA hay libertad de cátedra", añade, volviendo a caminar. "Tendrás muchos posibles maestros de entre los cuales elegir tus cursos". "Debes empezar por los cursos más amplios para después ir a los específicos", me dice escudriñando calle Bandera por algún lugar abierto. "Nada", murmura, y sigue caminando. De pronto, se para otra vez y chasquea los dedos. "¡Ah, ya sé, Mamay!”, exclama. Yo sólo atino a mirarlo confundida. "Piensa, Mamay, piensa”, me dice. "¿Qué lugar debe estar abierto porque tiene clientela que debe comer todos los días?" "Un lugar con huéspedes", contesto. “¡Un hotel!”, dice él. “¡El Hotel Carrera!”, añado yo, sintiendo que el alivio suelta otra vez las riendas del hambre. "Vamos, Mamay, Teatinos está sólo a dos cuadras" dice Murra caminando con paso firme. "Como ves, a menudo grandes problemas requieren de soluciones ingeniosas nada más", me dice. "Control vertical de la ecología", pienso yo, con una sonrisa, anticipando platillos deliciosos.

El Hotel Carrera siempre tuvo un aire imponente. En un Santiago nublado y casi vacío, las luces internas y las banderas colgando afuera de la fachada le daban al lugar un aspecto ligeramente amenazador. Murra comienza a subir las escaleras, claramente acicateado por el hambre. Yo, en cambio, dudo. Tengo apenas algunas monedas en el bolsillo y un billete doblado en algún lugar de mi chaquetón antilluvia, por seguridad. Presupuesto de estudiante pobre. Un anticipo de lo que sería mi economía doméstica por varios años desde ese momento. John Murra se detiene y me mira desde lo alto de las escaleras. "¿Qué pasa, Mamay?”, pregunta. Yo sólo atino a sonreír ligeramente. "¿Poca plata, no?”, dice. "No te preocupes, yo invito ahora", agrega. "La próxima vez, eso sí, pagas tú", me dice con un aire cómplice. No contesto y subo las escaleras casi corriendo, pensando en los manjares que nos esperan adentro.

La comida era, en efecto, deliciosa. Murra tenía esa rara habilidad de hacer de diálogos irrelevantes un vertedero de ideas divertidas, sofisticadas y exquisitas. Después de tantos años, luego de conocer múltiples lugares y personas variadas, aún creo que Murra era el ser humano más dedicado y sistemático en escuchar a los demás, que jamás haya encontrado. Durante ese almuerzo (que se transformó en unas once), hablamos de una multitud de temas y él nunca dejó de escuchar mis dichos, que por irremediablemente anodinos cualquier otro intelectual habría despachado sin piedad al basurero de las ideas aburridas. En cambio, entre delicias culinarias, John Murra me ayudó a planificar los próximos veinte años de mi vida. Al final de nuestra conversación, cuando ya la universidad para Master y Doctorado estaban elegidas, los maestros seleccionados y los cursos identificados, Murra me dio una la lección de vida cuyo recuerdo quedó indisolublemente en mi memoria. "Los estudiantes son fundamentales, Mamay, nunca se te olvide", me dijo de repente. “¿Cómo, así?", pregunté de buen humor, poco dispuesta a pensar mucho después de la opípara comida. "Porque son la vida que se renueva, sin ellos no existen los maestros", me respondió. Era claro que había tocado una fibra 
básica de su ética profesional. No pregunté nada más. Esa sería la primera vez que yo escucharía un término hoy cotidiano en la academia americana, "sexual harassement". "A los estudiantes se los cuida, son sagrados porque los maestros no existen sin ellos" agregó, mirándome serio.

Los mozos del Hotel Carrera empezaron a mirarnos con ligera hostilidad y, para no incomodar, decidimos irnos. A la salida, un viento frío nos recordó que aún era un día de invierno y plebiscito en el centro de Santiago. Subiéndose el cuello del abrigo, John Murra me preguntó: “¿Entonces sabes donde está la calle Victoria Subercaseaux o pensaste que ya estoy senil?", me soltó a quemarropa y sin escrúpulos. "No, no sé dónde está la calle Victoria Subercaseaux", le respondo con una sonrisa. "Pues vamos, te la tengo que mostrar", dice él enrumbando hacia el este. "¿Y qué importancia tiene esa dichosa calle?", pregunto yo, siempre de buen humor. "Ahí está la Comisión Fulbright, Mamay", dice Murra, imperturbable. “¿La Fulbright?”, digo yo. “Claro, o cómo crees que te vas a pagar viaje, estudios y estadía en USA?", me dice con una sonrisa. "¡Necesitas beca, pues Mamay!", añade y sigue caminando. A la distancia de casi veinte años, aún recuerdo a John Murra así, caminando por el centro de Santiago, de invierno, con el cuello del abrigo alzado, mostrándome la calle Victoria Subercaseaux.

Alguien toca a la puerta entreabierta de mi oficina. "Justo a tiempo", pienso. Me vuelvo y veo a Kathryn, mi advisee, aferrándose a su mochila y chaquetón para la nieve. Viene con el rostro descompuesto, se nota que ha debido correr. "Take it easy" (relájate), le digo al notar que tiene la respiración entrecortada. "Corrí escaleras arriba, Dra. Marsilli", dice ella. "Sé que a usted le molesta la impuntualidad", añade. Yo me limito a sonreír. "Debe pensar que soy una vieja quisquillosa", pienso. "What can I do for you? (¿en qué puedo ayudarte?)", le pregunto y le pido que se siente. "Necesito consejo, Dra. Marsilli", me dice ella con timidez. "¿Acerca de qué?", pregunto yo, acomodando descuidadamente el mar de papeles que inunda mi escritorio. "Quiero estudiar fuera de los US", dice ella. "En Chile" añade, para ser específica. La miro y le sonrío. "La vida que se renueva", me digo a mí misma y se me viene a la memoria otra vez un día de lluvia y plebiscito en el centro de Santiago. 
